\title{
Interplay between Local GABAergic Interneurons and Relay Neurons Generates $\gamma$ Oscillations in the Rat Olfactory Bulb
}

\author{
Samuel Lagier, ${ }^{\star}$ Alan Carleton, ${ }^{*}$ and Pierre-Marie Lledo \\ Laboratory of Perception and Memory, Centre National de la Recherche Scientifique, Unité de Recherche Associée 2182, Pasteur Institute, 75724 \\ Paris, France
}

Olfactory stimuli have been known for a long time to elicit oscillations in olfactory brain areas. In the olfactory bulb (OB), odors trigger synchronous oscillatory activity that is believed to arise from the coherent and rhythmic discharges of large numbers of neurons. These oscillations are known to take part in encoding of sensory information before their transfer to higher subcortical and cortical areas. To characterize the cellular mechanisms underlying $\gamma(30-80 \mathrm{~Hz})$ local field potential (LFP) oscillations, we simultaneously recorded multiunit discharges, intracellular responses, and LFP in rat $\mathrm{OB}$ slices. We showed that a single and brief electrical stimulation of olfactory nerve elicited LFP oscillations in the mitral cell body layer lasting $>1 \mathrm{sec}$. Both action potentials and subthreshold oscillations of mitral/tufted cells, the bulbar output neurons, were precisely synchronized with LFP oscillations. This synchronization arises from the interaction between output neurons and granule cells, the main population of local circuit inhibitory interneurons, through dendrodendritic synapses. Interestingly enough, the synchronization exerted by reciprocal synaptic interactions did not require action potentials initiated in granule cell somata. Finally, local application of a $\mathrm{GABA}_{\mathrm{A}}$ receptor antagonist at the mitral cell and external plexiform layers confirmed the exclusive role of the granule cell reciprocal synapses in generating the evoked oscillations. We concluded that interneurons located in the granule cell layer generate synaptic activity capable of synchronizing activity of output neurons by interacting with both their subthreshold and spiking activity.

Key words: interneuron; local field potential; mitral cell; olfaction; reciprocal synapse; synchronization

\section{Introduction}

Oscillatory synchronization has been found in several systems, in which it plays important roles in information processing, memory formation, and sensory perception (Varela et al., 2001). In the olfactory system, the inhalation of odor molecules was reported to trigger prominent $\gamma(30-80 \mathrm{~Hz})$ oscillations, already in the first central relay, the olfactory bulb $(\mathrm{OB})$ of mammals (Adrian, 1942; Bressler and Freeman, 1980; Freeman and Schneider, 1982; Bressler, 1984; Eeckman and Freeman, 1990; Chabaud et al., 2000) and its insect analog (Laurent and Naraghi, 1994). These evoked fast oscillations are thought to encode several features of a stimulus such as quality (Laurent and Davidowitz, 1994; Wehr and Laurent, 1996) and fine discrimination (Stopfer et al., 1997).

In addition to evidence supporting the use of time as a coding dimension, further investigations have also revealed the impor-

Received Dec. 18, 2003; revised March 11, 2004; accepted March 22, 2004.

This work was supported by the Pasteur Institute, Centre National de la Recherche Scientifique, Ministère déléguéà la Recherche et aux Nouvelles Technologies (Action Concertée Incitative Biologie du Développement et Physiologie Intégrative, 2003), and Annette Gruner-Schlumberger Foundation. We thank G. M. Shepherd and G. Laurent for helpful discussions.

*S.L. and A.C. contributed equally to this work.

Correspondence should be addressed to Pierre-Marie Lledo, Laboratory of Perception and Memory, Centre National de la Recherche Scientifique, Unité de Recherche Associée 2182, Pasteur Institute, 25 rue du Dr. Roux, 75724 Paris Cedex 15, France. E-mail: pmlledo@pasteur.fr.

A. Carleton's present address: Ecole Polytechnique Fédérale de Lausanne, Brain and Mind Institute, CH-1015 Lausanne, Switzerland. E-mail: alan.carleton@epfl.ch.

DOI:10.1523/JNEUROSCI.5570-03.2004

Copyright $\odot 2004$ Society for Neuroscience $\quad$ 0270-6474/04/244382-11\$15.00/0 tance of spatial patterns of activity (for review, see Kauer and White, 2001; Korsching, 2002; Leon and Johnson, 2003). Two combinatorial encoders thus seem to take part simultaneously in odor information processing (Laurent, 2002). The first one consists of the odorant receptor repertoire expressed by the sensory neuron ensemble, which transduces receptor activation patterns into functional maps. These spatial maps depend, at least partially, on the activity of inhibitory periglomerular interneurons. The secondary encoder lies in the deeper bulbar interneuron network that extracts higher-order features from the functional maps to convert topographical patterns as temporal relationships across the firing output neuron ensemble. It is thus clear that spatial and temporal patterns are tightly controlled by distinct populations of local interneurons, but their respective role yet remains to be characterized.

In the mammalian $\mathrm{OB}$, the precise nature of networks generating $\gamma$ oscillations of local field potential (LFP) is highly debated. Previous theoretical investigations have suggested that granule cells, the largest population of bulbar interneurons, constitute the main generators of extracellular current flows (Rall and Shepherd, 1968; Freeman, 1975), but in vivo data supporting this assumption came out only recently (Neville and Haberly, 2003). The relative contribution of granule cells and bulbar output neurons (i.e., mitral/tufted cells) implicated in fast oscillations still remains speculative, although a phase relationship between mitral/tufted cell spiking activity and LFP oscillations has been found (Kashiwadani et al., 1999; Buonviso et al., 2003). 
In addition, although clearly $\gamma$ oscillations originate from intrinsic bulbar circuitry because they are abolished in the piriform cortex by OB removal (Becker and Freeman, 1968) and preserved when conduction through the olfactory peduncle is blocked (Gray and Skinner, 1988; Neville and Haberly, 2003), the cellular mechanisms responsible for their maintenance are still unknown. Previous analysis of LFP oscillations suggested distinct mechanisms including: (1) a fast synaptic inhibitory feedback loop between mitral/tufted cells and granule cells (Mori and Takagi, 1977; Gray and Skinner, 1988; Eeckman and Freeman, 1990; Nusser et al., 2001; Friedman and Strowbridge, 2003); (2) intrinsic membrane properties of mitral/tufted cells (Desmaisons et al., 1999); (3) odorant-induced sensory neuron oscillations (Nikonov et al., 2002); and (4) electrical couplings between interneurons (Friedman and Strowbridge, 2003). A fuller understanding of the mechanisms generating LFP oscillations, as well as the temporal relationship between unit recordings and population dynamics, is thus required.

Here, we investigate the mechanisms of field oscillations in rat OB slices. With simultaneous LFP, multiunit, and intracellular recordings, we demonstrated that mitral/tufted cells were the only neuronal population whose spike discharges and subthreshold oscillations were phased with extracellular oscillations. Remarkably, we found that LFP oscillations required the inhibitory action provided by granule cells through local processing, not requiring action potentials generated in their somata.

\section{Materials and Methods}

Slice preparation. Experiments were performed in $\mathrm{OB}$ slices obtained from 3- to 5-week-old Wistar rats provided by Janvier (Le Genest St. Isle, France). Animals were anesthetized by isoflurane (Belamont, Neuillysur-Seine, France) inhalation before decapitation. Most of the forebrain was rapidly removed and immediately placed in a $4^{\circ} \mathrm{C}$ normal artificial CSF (ACSF) solution. The ACSF contained (in mM): $124 \mathrm{NaCl}, 3 \mathrm{KCl}, 2$ $\mathrm{CaCl}_{2}, 1.3 \mathrm{MgSO}_{4}, 25 \mathrm{NaHCO}_{3}, 1.2 \mathrm{NaH}_{2} \mathrm{PO}_{4}$, and 10 D-glucose, $\mathrm{pH} 7.3$ when bubbled with $95 \% \mathrm{O}_{2}$ and $5 \% \mathrm{CO}_{2}$. Horizontal slices $(300 \mu \mathrm{m})$ were cut with a vibrating microslicer (DTK-1000; Dosaka), kept in normal oxygenated ACSF at $32^{\circ} \mathrm{C}$ for $\sim 60 \mathrm{~min}$, and then stored at $20^{\circ} \mathrm{C}$ before the experiment. For electrophysiological recordings, individual slices were transferred to a submerged chamber where they were superfused with oxygenated ACSF and warmed at $35-37^{\circ} \mathrm{C}$ at a rate of $2-3 \mathrm{ml} / \mathrm{min}$.

Electrophysiological recordings. LFPs and extracellular multiunit discharges were recorded using glass micropipettes (Clark Electromedical Reading, UK) pulled with a Flaming-Brown horizontal puller (P-87; Sutter Instruments, San Rafael, CA) and filled with $2 \mathrm{M} \mathrm{NaCl}$ (DC resistance, 1-5 M $\Omega$ ). Extracellular recordings were amplified using an IsoDAM8 differential amplifier (World Precision Instruments, Hertfordshire, UK) and then amplified and differentially filtered $(10-100 \mathrm{~Hz}$ for LFP and $0.3-3 \mathrm{KHz}$ for units). Intracellular recordings were performed with borosilicate glass microelectrodes pulled with the P-87 microelectrode puller. Intracellular recordings in the current-clamp mode (electrode resistances ranged from 100 to $140 \mathrm{M} \Omega$ or from 50 to $80 \mathrm{M} \Omega$ when filled with $2 \mathrm{M}$ potassium acetate or potassium chloride, respectively) were controlled through an Axoclamp-2B amplifier (Axon Instruments, Foster City, CA), and during experiments, the bridge balance was continuously monitored. Only mitral/tufted cells having stable membrane potentials negative to $-55 \mathrm{mV}$, input resistances of $>80 \mathrm{M} \Omega$, and action potentials overshooting $0 \mathrm{mV}$ were collected for analysis. At the end of each experiment, measuring the DC offset of the electrode in the bathing medium controlled changes in electrode tip potential, and the value of the measured membrane potential was corrected accordingly. Changes in electrode tip potential were usually $<3 \mathrm{mV}$. Data were collected online with a Digidata 1200 interface (Axon Instruments). To evoke synaptic responses, stimuli ( $100 \mu \mathrm{sec}$ duration, $50 \mathrm{~V}, 15 \mathrm{sec}$ intervals) were delivered through fine bipolar tungsten electrodes located in the olfactory nerve layer.
Solutions and drugs. Drug solutions were bath-applied using a gravitydriven perfusion system except for focal applications done with a pressure system and visually controlled with methylene blue present in the application glass pipettes. To block IPSPs mediated by the activation of ionotropic $\mathrm{GABA}_{\mathrm{A}}$ receptors, slices were bathed with a $\mathrm{GABA}_{\mathrm{A}}$ receptor antagonist (20 $\mu \mathrm{M}$ SR95531 or bicuculline methiodide). For a local puff, SR95531 was used at $50 \mu \mathrm{M}$. To block EPSPs, slices were bathed with a nonspecific ionotropic glutamate receptor antagonist, kynurenic acid (5 $\mathrm{mM}$ ), or in the presence of the NMDA receptor antagonist D,L-2-amino5-phosphonopentanoic acid (D,L-APV, $100 \mu \mathrm{M})$ applied with the nonNMDA receptor antagonist 1,2,3,4-tetrahydro-6-nitro-2,3-dioxobenzo [f] quinoxaline-7-sulfonamide (NBQX, $20 \mu \mathrm{M}$ ). All drugs and salts were purchased from Sigma (St. Quentin Fallavier, France).

Data analysis. Both on- and off-line analyses were performed with Elphy (Gérard Sadoc, Centre National de la Recherche Scientifique) associated with homemade software. An offline supplementary filtering (high-pass Bessel filter, $>10 \mathrm{~Hz}$ for LFP and $>300 \mathrm{~Hz}$ for units) was used. Counting events crossing a threshold adapted to each recording, to discriminate spikes from the noise, was used for spike detection. Averaging of blocks of the trial aligned to the stimulation using bins of 2-20 msec was performed to construct peristimulus time histograms (PSTHs). The phase of each detected spike was calculated relative to the neighboring peaks of the LFP according to the equation:

$$
\varphi=360 \times \frac{t_{\text {spike }}-t_{\text {lastLFPpeak }}}{t_{\text {nextLFPpeak }}-t_{\text {lastLFPpeak }}},
$$

where $\varphi$ is the spike phase; $t_{\text {spike }}$ is the date of spike detection; $t_{\text {lastLFPpeak }}$ is the date of the preceding LFP peak, set as $0^{\circ}$; and $t_{\text {nextLFPpeak }}$ is the date of the following LFP peak, set as $360^{\circ}$. LFP and PSTH analysis were calculated using 200 and $1200 \mathrm{msec}$ time windows, respectively. The sliding autocorrelations were computed with $200 \mathrm{msec}$ time windows slid forward with 10 msec steps. A normalized fast Fourier transform (FFT) power was used to evaluate the effect of drug applications on induced $\gamma$ LFP oscillations. This index of oscillation $(I)$ was calculated according to the equation:

$$
I=\frac{\int_{20}^{100} F F T_{\text {post }} d \nu}{\int_{20}^{100} F F T_{\text {pre }} d \nu},
$$

where $F F T_{\text {post }}$ is calculated on sweeps after the stimulation, and $F F T_{\text {pre }}$ is calculated on the same sweeps before the stimulation. The percent variations was then calculated by setting the average value of $\gamma$ oscillations in the presence of glutamate receptor antagonists to $0 \%$ and before any pharmacological application, to $100 \%$. Because phasing any event to a periodic function generates circular data, we used circular statistical tests that were computed using Oriana 2 (Kovach Computing Services, Pentraeth, Wales). Many of the basic statistical parameters are based on the concept of the mean vector. A group of observations (or individual vectors) has a mean vector that can be calculated by combining each of the individual vectors. The mean vector will have two properties: its direction (the mean angle) and its length. The length will range from 0 to 1; a larger value indicates that the observations are clustered more closely around the mean than a lower one. To ascertain the level of significance, we used a combination of three different circular tests (Fisher, 1993). This is necessary especially when the length of the vector is low and because of the use of very high samples in our case. Rayleigh's uniformity test was used to calculate the probability of the null hypothesis that the data are distributed in a uniform manner. Watson's test is a goodnessof-fit test against a uniform distribution. Finally, Kuiper's test takes the alternative approach of directly comparing the distribution of the data with the uniform distribution. All sample sizes are expressed in numbers of slices, and the level of significance was set to $p=0.05$. Unless otherwise indicated, data are expressed as mean \pm SEM. 
Results

Stimulation of the olfactory nerve triggered long-lasting LFP oscillations

To study the collective behavior of bulbar output neuron firing, extracellular field potential recordings were performed at the border between the mitral cell body layer (MCL) and the external plexiform layer (EPL). Orthodromic stimulation of the sensory neuron axons, above and slightly rostral to the recording site, was used to evoke field responses (Fig. $1 A$ ). We found that a single and brief (100 $\mu \mathrm{sec})$ electrical shock consistently induced fast LFP oscillations (Fig. $1 B ; n=134$ slices). In contrast, mitral/tufted cell LFP exhibited no obvious rhythmic activity in the absence of stimulation (Fig. $1 B-E$ ). Oscillations were induced by the network stimulation because bath application of blockers of the ionotropic glutamate synaptic transmission (kynurenate, $5 \mathrm{~mm}$, or a mixture of NBQX, $10 \mu \mathrm{M}$, and D,L-APV, $100 \mu \mathrm{M})$ completely abolished them $(n=40$; also see Fig. $5 A$ ). To analyze the frequency and degree of these evoked oscillations, we used both FFT (Fig. 1C) and autocorrelation computations (Fig. 1D). The power spectra of field potentials and the autocorrelogram obtained before, during, and after olfactory nerve stimulation (Fig. $1 B$ ) indicate a dominant frequency at $\sim 50 \mathrm{~Hz}$ occurring only after stimulation (Fig. $1 C, D)$. Overall, these evoked oscillations correspond to the $\gamma$ range; the mean frequency was $44.6 \pm 8.9 \mathrm{~Hz}$, ranging from 21 to $77 \mathrm{~Hz}$ (Fig. $1 F$ ). To analyze the dynamics of these oscillations, we further performed sliding autocorrelations, which represent the progressive changes of the correlation function after stimulations. Figure $1 E$ illustrates an example in which field oscillations, triggered by brief olfactory nerve stimulation, took several seconds to decay. These observations provided unambiguous evidence that the OB network is able to generate robust and long-lasting oscillations even when maintained in vitro.

\section{Field oscillations are generated in the MCL region}

To determine the region where $\gamma$ oscillations were generated, we performed simultaneous triple-LFP recordings in different OB layers (Fig. $2 A ; n=7$ ). Three electrodes were respectively placed in the glomerular layer (GL electrode), at the border between MCL and EPL (MCL electrode), and in the granule cell layer (GCL electrode). Olfactory nerve stimulation induced reliable $\gamma$ oscillations at all recording sites (Fig. $2 B_{1}$ ). This may indicate either the presence of three different oscillatory generators or the spread of the oscillatory activity from a single generator throughout different layers. The latter hypothesis is more likely because the three signals had highly similar dynamics, as shown by superimposing the different traces (Fig. $2 B_{2}$ ). Both FFT (Fig. 2C) and autocorrelograms (Fig. 2D) indicated similar oscillatory characteristics. In particular, the average period calculated between the peak at 0 and the first satellite peak is not significantly different $(20.3 \pm 1.4,20.2 \pm 1.5$, and $20 \pm 1.4 \mathrm{msec}$, for GL, MCL, and
GCL, respectively; $p>0.05$ with the paired $t$ test for all combinations; $n=7$; Fig. $2 G$ ). As a consequence, a similar period is found in cross-correlograms between the different signals (19.5 \pm 3.6 and $20.6 \pm 3.7 \mathrm{msec}$ for the cross-correlation between MCL-GL and MCL-GCL, respectively; $p>0.05$ with the paired $t$ test for all combinations; Fig. $2 E-G$ ). In addition, MCL signals constantly preceded both GL and GCL signals by a few milliseconds (for the cross-correlation between MCL-GL and MCLGCL, $-3.3 \pm 1.8$ and $-2.1 \pm 2 \mathrm{msec}$, respectively), suggesting that field oscillations were first generated in the MCL before propagating to the overlying layers. Consistent with this, in all our experiments, the signals recorded from the MCL electrode had the greatest amplitude $(10.2 \pm 1.6$ and $5.4 \pm 1.2 \mu \mathrm{V}$ for the MCL and GCL, respectively; $p<0.001$ with the paired $t$ test; Fig. $2 B_{1}$ ), whereas those measured in the GL were consistently the smallest $(1.9 \pm 0.4 \mu \mathrm{V} ; p<0.005$ when compared with GCL with the paired $t$ test). Similar results were obtained with FFT analysis (Fig. $2 F$ ). Both the maximum amplitude and the integral values of the FFT were systematically higher in the MCL than in the GCL and the GL. Furthermore, we noted that the signals recorded near the MCL were always similar to those in the GL but opposite to the signals from the GCL (Fig. $2 B_{2}$ ). This is indicated by the sign of the cross-correlation peaks $\left(3.4 \pm 0.9\right.$ and $-8.4 \pm 2.9 \mu \mathrm{V}^{2}$ for the MCL-GL and MCL-GCL cross-correlations, respectively; $p<0.01$ with paired $t$ test; Fig. $2 E$ ). Thus, our data revealed that 
A
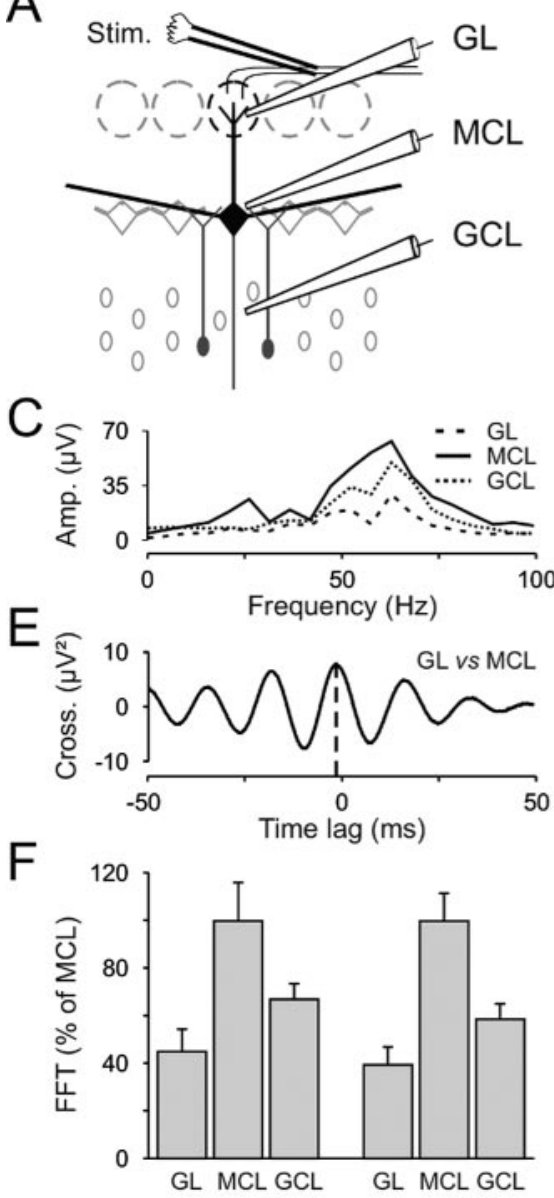

Amp. max. Integrale
$\mathrm{B}_{1}$

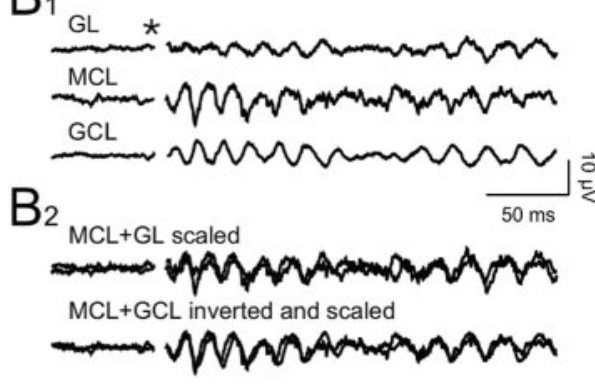

$\mathrm{D}$
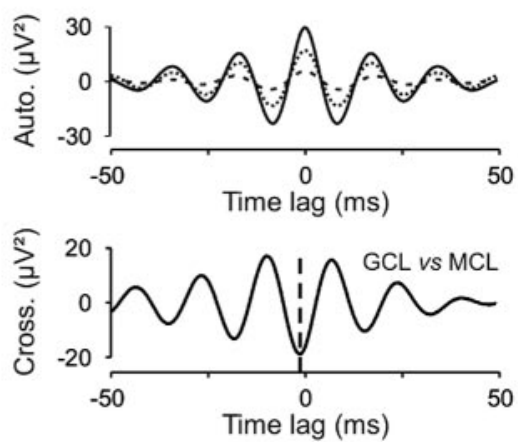

G

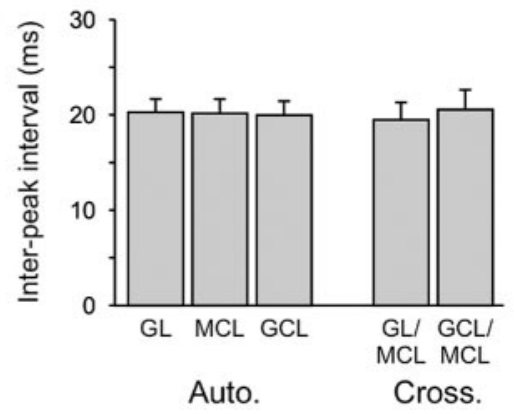

Figure 2. Simultaneous recordings in the different layers of the $O B$ reveal the origin of LFP oscillations. $A$, Recording protocol. Three electrodes were placed simultaneously in the GL (top electrode), the GCL (bottom electrode), and at the border between the MCL and the EPL (middle electrode). Stim., Stimulus. $B_{1}$, The olfactory nerve stimulation induced LFP oscillations in the three layers. The star indicates the stimulus onset. B2, Scaling (for the GL, GCL traces) and inversion (only for the GCL trace) of the traces in $B_{7} . C, D, F F T$ ( $C$ and autocorrelograms ( $D$ ) of the traces shown in $B . E$, Cross-correlations of the $\mathrm{GL}$ and $\mathrm{MCL}$ (left plot) and the $\mathrm{GCL}$ and $M C L$ (right plot) signals. Note that the maximum peaks occur just before $0 \mathrm{msec}$ (dashed line) and are, respectively, positive and negative for the $\mathrm{GL}-\mathrm{MCL}$ and $\mathrm{GCL}-\mathrm{MCL}$ cross-correlations. F, Quantification of FFT maximal amplitude (Amp. max.) and integral $(20-100 \mathrm{~Hz}$ ) for the three different recording locations ( $n=7$ slices). Note that the biggest signals were recorded at the border of the MCL. G, Mean periods found in the different recording locations calculated from the autocorrelograms (Auto.) and cross-correlograms (Cross.; $n=7$ slices).

most of the extracellular current flows that participate in LFP oscillations were generated in the EPL, next to the MCL.

\section{Mitral/tufted cell spikes and subthreshold activities are phased with field oscillations}

To examine the neural substrates of these evoked LFP oscillations, multiunit discharges from the mitral/tufted cells and from the two populations of bulbar interneurons were analyzed (for the recording configuration, see Fig. $3 A$ ). As shown in the PSTH, olfactory nerve stimulation evoked reliable firing patterns in both relay and local neurons (Fig. $3 B$ ). Afferent stimulation triggered a phasic increase in spike rate of both mitral/tufted cells and granule cells, followed by a long-lasting (up to $3 \mathrm{sec}$ ) excitation of mitral/tufted cells (Fig. 3B; also see supplemental Fig. 1, available at www.jneurosci.org). Most of putative periglomerular interneurons exhibited slow oscillatory responses (Fig. 3C; a period of $206 \pm 44 \mathrm{msec} ; n=11$ of 18 ). This latter finding supports recent observations revealing a slow rhythmic activity in the glomerular layer (MacQuiston and Katz, 2001; Puopolo and Belluzzi, 2001; Schoppa and Westbrook, 2001; Hayar et al., 2004). In contrast, no rhythmic activity could be seen in either averaged PSTHs and their autocorrelograms (Fig. 3B,C) or in interspike interval plots (data not shown) of mitral/tufted and granule cells activity. This strongly suggests that these cell types were not synchronized by the olfactory nerve stimulations per se.

Because the previous results were averages and could thus mask phenomena in their own variability, we focused on individual sweeps. As shown on single MCL multiunit raster plots, spikes from mitral/ tufted cells were not homogeneously distributed over time (Fig. 3D, MCL units). Groups of spikes could be clearly seen, with an occurrence linked to LFP oscillations (Fig. 3D, gray boxes). No similar pattern was found in glomerular and granule cell layer units (Fig. 3D, GL, GCL units).

We therefore further examined the temporal relationship between the multiunit spikes of the different neuronal populations and the phase of LFP oscillations (Fig. 3E). We found that mitral/tufted cells reliably discharged in phase with the LFP oscillations $\left(n=12\right.$ of $12 ; p<10^{-10}$ with Rayleigh's test). The highest probability of action potential occurrence in mitral/ tufted cells was very reliable across experiments and corresponded to the descending phase of the oscillation (average direction, $118 \pm 3^{\circ}$; range, $104-136^{\circ}$; Fig. $3 E$, middle plot). In contrast, interneuron spikes were only rarely phased to the LFP ( $n=3$ of 5 and 3 of 10 for periglomerular neuron and granule cell units, respectively; $p<0.05$ with Rayleigh's test), and the phasing was very week (i.e., low vector length and high probability). The preferred occurrences were on average $144 \pm$ $19^{\circ}$ (range, $114-180^{\circ}$ ) and $111 \pm 4^{\circ}$ (range, $105-119^{\circ}$ ) for periglomerular neuron and granule cell units, respectively (Fig. $3 \mathrm{E}$, left, right plots). Of note is the fact that these results did not vary with the position of the recording sites in the layers (data not shown). This analysis thus reveals mitral/tufted cell rhythmicity because the reference (i.e., LFP oscillations) has the same variability, which is not the case for average PSTHs or even interspike interval plots.

To further investigate the link between mitral/tufted cell activity and LFP oscillations, simultaneous field and intracellular recordings were performed (Fig. $4 \mathrm{~A}$ ). As found in extracellular recordings, mitral/tufted cell spikes recorded intracellularly were phased with LFP oscillations (Fig. $4 B, D_{1}, E ; n=5$ of 5 ). The average direction was $118 \pm 6^{\circ}$ (range, $103-140^{\circ} ; p<10^{-10}$ with Rayleigh's test). Riding on the long depolarization response induced by the olfactory nerve stimulation, subthreshold oscillations of mitral/tufted cell membrane potentials were also phased with LFP (Fig. $4 B$ ). Peaks of membrane oscillations occurred at $200 \pm 5^{\circ}\left(n=5\right.$ cells, 2367 events; $p<10^{-10}$ with Rayleigh's test $)$ 
of LFP oscillations (Fig. 4F). We have previously reported that such oscillations represent the summation of intrinsic membrane oscillations and IPSP (Desmaisons et al., 1999). When intrinsic subthreshold oscillations were isolated, they were clearly phased with the trough of the LFP (Fig. $4 \mathrm{D}_{2}$ ).

When cells were kept at their resting membrane potential, both spikes and membrane subthreshold oscillations were elicited by the stimulation (Fig. 4C). After a slight hyperpolarization, spikes were not further observed, whereas putative IPSPs and intrinsic membrane oscillations could still be monitored (Fig. 4C, legend). Because the latter are voltage-sensitive (Desmaisons et al., 1999), mitral/tufted cells were further hyperpolarized to isolate IPSPs. To demonstrate that the isolated hyperpolarizing potentials, such as those displayed in Figure 4, $C_{2}$ (right plot) and $D_{3}$, reflect truly GABAergic events, we performed intracellular recordings aimed at changing the chloride equilibrium potential. When mitral/tufted cells were hyperpolarized with a high-chloride intracellular solution $(2 \mathrm{M} \mathrm{KCl})$, all membrane potential responses turned to depolarizing $(n=5$; supplemental Fig. 2$)$. We thus concluded that membrane potential deflections seen in hyperpolarized cells were mediated by the $\mathrm{GABA}_{\mathrm{A}}$ receptor-gated, chloride dependent ionic conductance. We analyzed the relationship between IPSPs, recorded in hyperpolarized cells in K-acetate (2 M), and LFP (Fig. 4C) and found the highest probability of occurrence at $359 \pm 9^{\circ}$ of the oscillation $(n=5$ cells, 1520 events; $p<10^{-8}$ with Rayleigh's test). This corresponded to the peak of the oscillation (Fig. $4 D_{3}, G$ ).

LFP oscillations require a synchronization of the suprathreshold and subthreshold activities of groups of neurons to emerge (Gray, 1994). In the OB, mitral/tufted cell activities were tightly phased with LFP oscillations, as well as with inhibitory inputs received by mitral/tufted cells. Even if it was hard to determine experimentally the relative contribution of these electrical events to the extracellular recorded signals, we assumed that this tight relationship contained information about the mechanisms of neuronal synchronization. For this reason, we investigated pharmacologically the origin of the rhythmic inhibition received by mitral/tufted cells.

\section{$\mathrm{GABA}_{\mathrm{A}}$ receptor antagonists impaired LFP oscillations}

It has been previously reported that reducing GABAergic synaptic transmission in transgenic mice changed $\gamma$ frequency oscillations in the mouse OB (Nusser et al., 2001), and that the synchronization of output neuron responses, evoked by odorant presentations, was altered by local applications of a $\mathrm{GABA}_{\mathrm{A}}$ receptor antagonist into the bulbar homologous structure in insects (MacLeod and Laurent, 1996). Here we investigated whether induced LFP oscillations were similarly sensitive to a
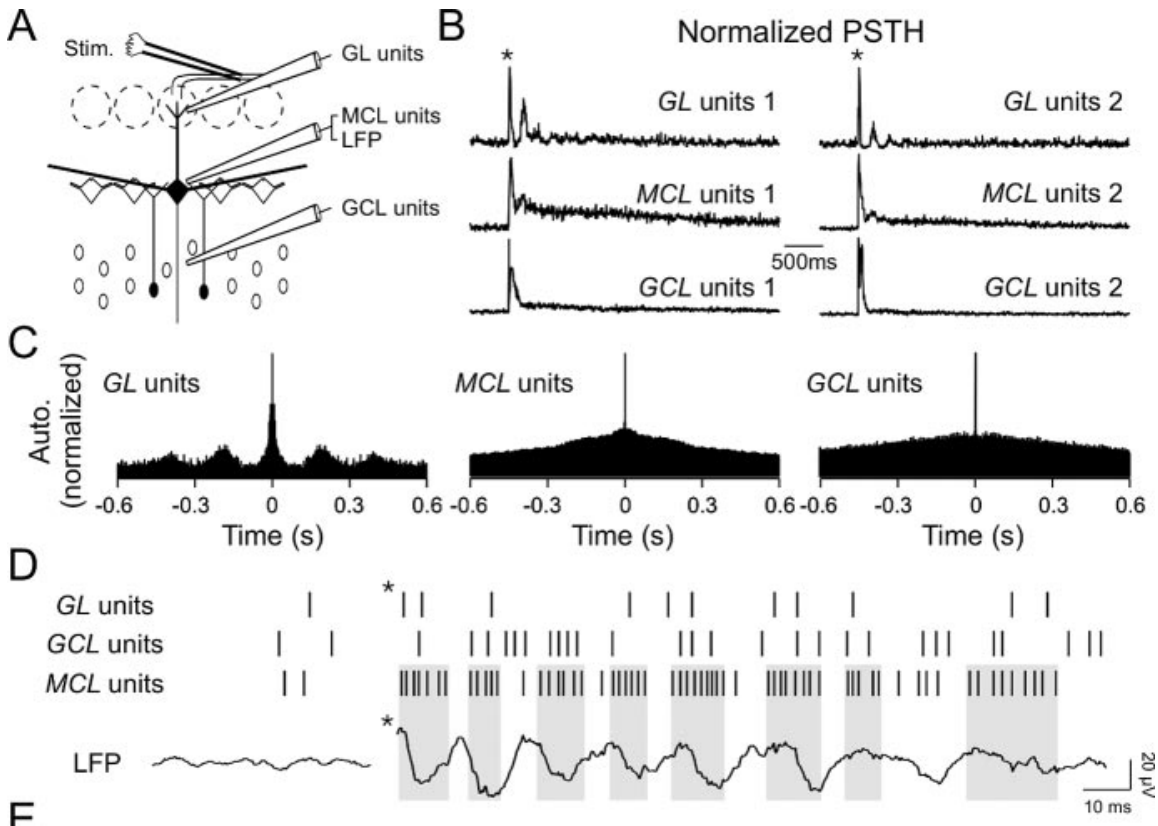

Figure 3. LFP oscillations reflect mitral/tufted cells synchronization. $A$, Experimental scheme. Extracellular signals are filtered 作 coincidence with LFP descending phases (gray boxes). The star indicates the stimulus onset. $E$, Mean distribution of action potentials relative to the phase of LFP oscillations recorded near the MCL (solid line) for the glomerular layer interneurons (left 作 $0.12-0.25$ ), and for granule cells (right plot; average length, $0.1 \pm 0.03$; range, $0.06-0.15$ ). The gray box in the middle plot represents the period of highest occurrence probability of mitral/tufted cells firing, as shown in $D$. The dashed line represents a theoretical uniform distribution for comparison.

pharmacological manipulation of the fast GABAergic synaptic transmission. Bath applications of $20 \mu \mathrm{M}$ SR95531, a specific $\mathrm{GABA}_{\mathrm{A}}$ receptor antagonist $(n=5$; Fig. $5 A)$, bicuculline methiodide $(n=12$; data not shown), or picrotoxin $(n=3$; data not shown) were all found to abolish LFP oscillations. Figure $5 B$ shows that LFP oscillations seen in control conditions were dramatically reduced during SR95531 treatment. This effect was consistent in all tested slices (12.8 $\pm 6.9 \%$ of control; $n=5 ; p<$ 0.005 ) and was fully reversible after the drug washout (Fig. 5B). The effect of all antagonists could be either attributed to a direct involvement of GABAergic synaptic events in inducing oscillations or to an indirect mechanism resulting from a depolarization of the whole network, thus inactivating voltage-gated $\mathrm{Na}^{+}$channels. This is, however, not the case because we were still able to record mitral/tufted cell units during the antagonist application (Fig. 5A, PSTH, $C$, summary graph). The firing rate of individual mitral/tufted cells was increased fourfold in the presence of SR95531 but never exceeded $90 \mathrm{~Hz}(n=4$ mitral cells intracellularly recorded; data not shown). Nevertheless, our data do not exclude indirect effects of SR95531 application on intrinsic prop- 
A
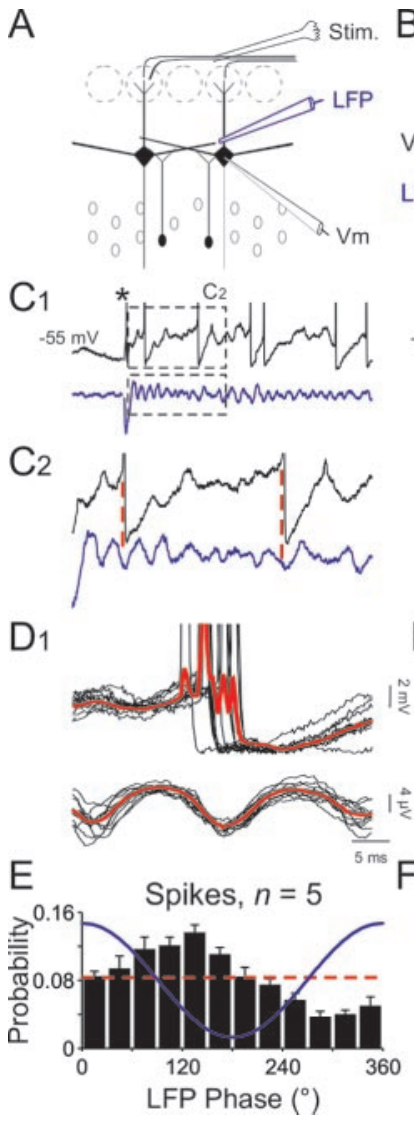
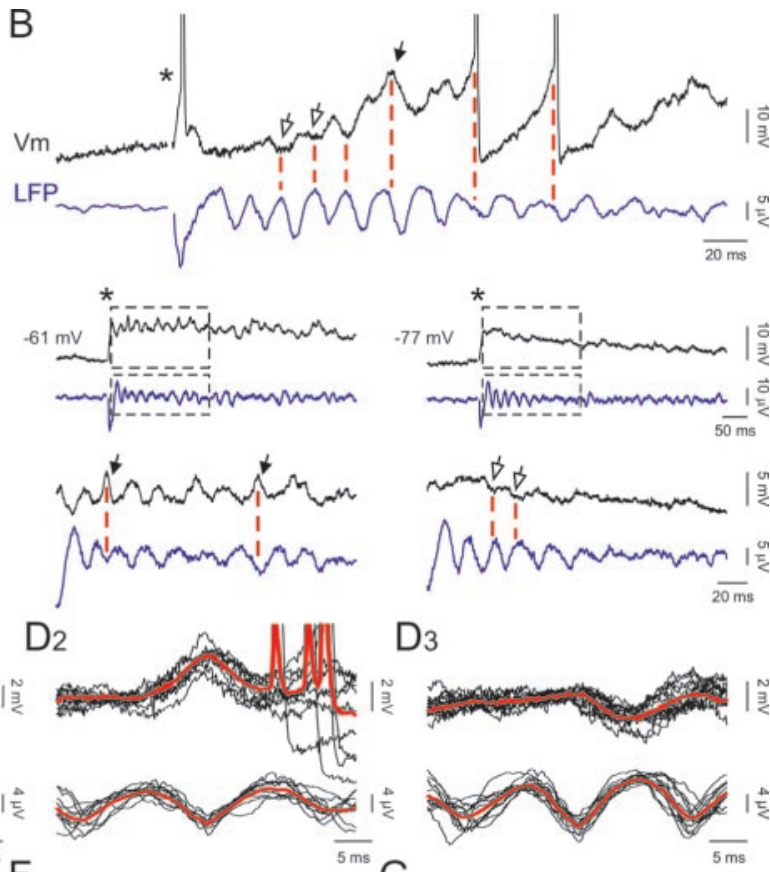

Subth. oscill., $n=5$
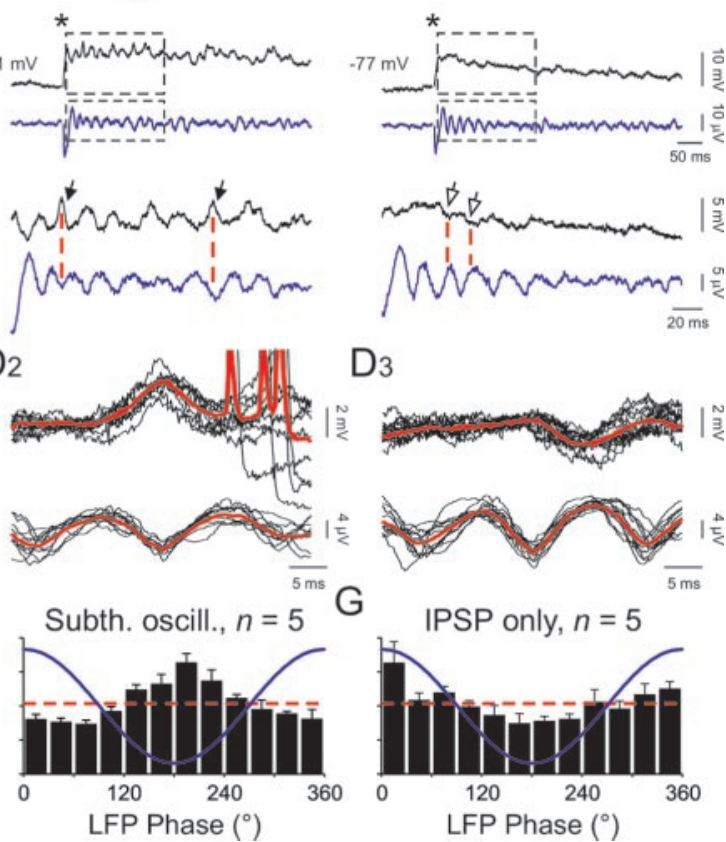

D3
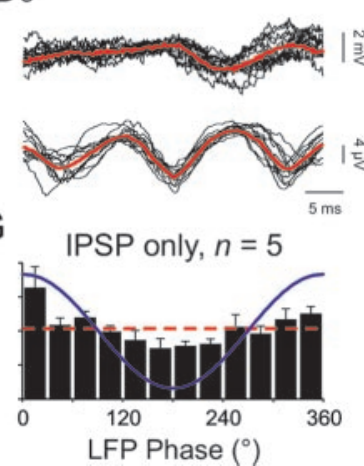

Figure 4. Mitral/tufted cell suprathreshold and subthreshold activities are precisely linked with LFP oscillations. $A$, Experimental scheme. Stim., Stimulus. B, Simultaneous LFP and a mitral cell intracellular recording $(\mathrm{Vm}$ ) revealing the phasing of IPSPs (open arrows), putative intrinsic oscillations (black arrow), and action potentials (truncated) with LFP oscillations. $C_{1}$, Simultaneous LFP and mitral cell intracellular recordings with progressive hyperpolarization of the same recorded cell in $B . \ln B$ and $C_{1}$, the star indicates the stimulus onset. $C_{2}$, Enlargements of traces shown in $C 1$ (black dashed boxes). Note that a slight hyperpolarization prevents the emission of spikes (middle plot) and reveals the phasing of putative intrinsic subthreshold oscillations with LFP (black arrows). A further hyperpolarization suppresses intrinsic membrane oscillations (right plot) and reveals the phasing of IPSPs (open arrows). $D_{1}$, Alignment and superimposition of simultaneous intracellular (top black lines) and LFP (bottom black lines) recordings and their respective averages (red lines) revealing that spikes principally occur during the descending phase of LFP oscillation. $D_{2}$, Same procedure as in $D_{1}$ revealing that peaks of membrane oscillations principally occur during troughs of the LFP oscillations. $D_{3}$ Same procedure as in $D_{1}$ but with hyperpolarized cells revealing that IPSPs principally occur during peaks of LFP oscillations. $E-G$, Mean distribution of intracellular spikes $(E)$, membrane subthreshold oscillation (Subth. oscill.) peaks $(F$ ), and IPSPs $(G)$ relative to the phase of the LFP oscillation (blue line). The theoretical uniform distribution is represented by the dashed red line for comparison.

erties of mitral/tufted cells (e.g., inactivation of slow potassium channels or depletion of glutamate-containing vesicles).

Finally, to demonstrate that LFP oscillations resulted from primary afferent inputs and not directly from electrical stimulation alone, $100 \mu \mathrm{M}$ APV and $10 \mu \mathrm{M}$ NBQX were bath-applied. As shown in Figure 5B, these antagonists abolished the LFP oscillations. Neither the amplitude nor the integral of the FFTs computed after the stimulation was different from that calculated before the stimulation in the presence of APV and NBQX ( $p=$ 0.38 and 0.44 , respectively, with the paired $t$ test; $n=8$ ).

To characterize the type of inhibitory interneuron responsible for generating LFP oscillations, we performed focal application of SR95531 to block GABAergic synapses selectively made either by granule cells or periglomerular neurons onto mitral/tufted cells. As shown in Figure 6A, a decrease of field oscillations was seen during focal application of SR95531 at the border of the MCL (a mean reduction of $46.6 \pm 6.5 \%$ of the power spectra in the $\gamma$ range; $p<0.005 ; n=7)$. This effect is specific because similar puff applications of ACSF did not affect the LFP oscillations $(n=$
$4 ; 96.5 \pm 4.5 \%$ of the control; paired $t$ test, $p=0.57$; data not shown). Then, when the puff pipette was moved to the GL, the same focal application did not alter the LFP signal (mean reduction of $10.1 \pm 10.4 \%$; $p>$ $0.05 ; n=7$; Fig. $6 B, C)$. In both cases, the drug efficacy was revealed by the increase of firing discharges $(p<0.005 ; n=7$ in both cases; Fig. $6 D$ ). Finally, when the puff pipette was located back to the border of the MCL during the same recordings, once again LFP oscillations were dramatically reduced (mean reduction of $40.2 \pm 8.9 \%$; $p<0.005 ; n=4)$. As shown in Figure 6C, the washout of SR95531 after local application was accompanied by a rebound effect (five of seven slices). On average, the oscillation index was potentiated after a washout of $10 \mathrm{~min}$, but this enhancement did not reach statistical significance $(149.4 \pm 22.5 \%$ of control; $p=0.08 ; n=$ 7). This effect was accompanied by a slight reduction in mitral/tufted cell firing rates, not reaching statistical significance (7.9 \pm 1.8 spikes/100 msec vs $10.8 \pm 0.9$ spikes/ $100 \mathrm{msec}$ in control; $p>0.5 ; n=7$; Fig. $6 D)$. To investigate whether such a potentiation resulted from disinhibition of granule cells, SR95531 was further locally applied in the GCL. No effect was found either on LFP oscillations $(102.7 \pm 6.6 \%$; $p>0.05 ; n=5)$ or on mitral/tufted cells discharge (116 $\pm 13 \% ; p>0.05 ; n=5)$. Thus, the origin of this rebound is still unknown.

The reciprocal synapse as a key element to generate $\gamma$ band LFP oscillations

As indicated above, two arguments support the crucial role of dendrodendritic inhibition to generate LFP oscillations. First, their blockade dramatically reduced the oscillations, and, second, mitral/tufted cells received IPSPs phased with LFP oscillations. However, recordings of granule cell discharges revealed that their firing was not consistently phased with LFP oscillations (Fig. 3D). Nevertheless, it has been shown that the inhibition provided by granule cells is partly independent of spiking activity (Jahr and Nicoll, 1982; Chen and Shepherd, 1997; Isaacson and Strowbridge, 1998; Schoppa et al., 1998; Castillo et al., 1999; Halabisky et al., 2000). Thus, this could explain the apparent contradiction between the requirement of IPSPs for generating LFP oscillations and the absence of a temporal relationship between granule cell firing and LFP oscillations. To assess this, we performed dual LFP recordings in the MCL and the GCL (Fig. 7A) while using a third manipulator holding a small blade. During the course of the experiment the blade was progressively lowered with a motorized micromanipulator to disrupt the MCL from the GCL (for the recording configuration, see Fig. $7 A$ ) and thus to isolate granule cell dendrites from their soma. The blade was lowered as close to the MCL as possible to minimize the participation of granule cells located close to the MCL. In this case, the intact proportion of GCL was never exceeding $20 \%$ of the total 
A

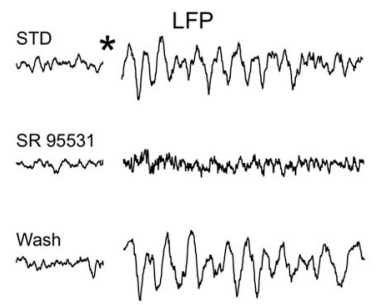

NBQX+APV

B

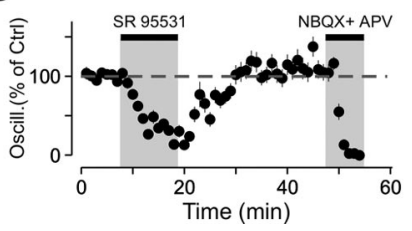

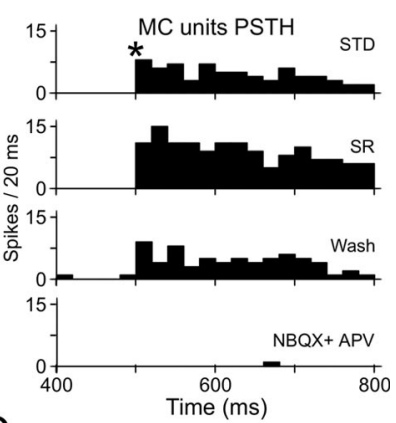

C

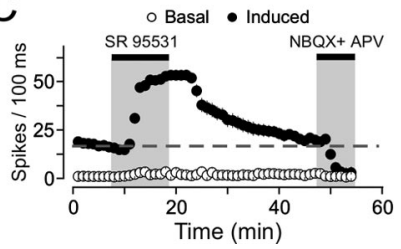

Figure 5. LFP oscillations require inhibition to appear. A, LFP recordings (left plot) and corresponding mitral/tufted cells population PSTH (MC units PSTH; right plot) under different pharmacological conditions. Note the disappearance of oscillations and the increase in mitral/ tufted cell discharge during bath application of SR95531 (SR). Bath application of NBQX and APV completely blocks both oscillations and mitral/tufted cells discharge. STD, Standard conditions. $B$, Average of five experiments showing the evolution of LFP oscillations over time. C, Average of five experiments showing the evolution of mitral/tufted cells discharge over time. Note the absence of variation of the baseline firing rate. The dashed line represents the mean induced firing rate in control conditions.

size of the layer. The length of the cut $(\sim 1500 \mu \mathrm{m})$ was longer than the length of mitral/tufted cell secondary dendrites and the width of granule cell arborization. As described above, olfactory nerve stimulation induced robust LFP oscillations in both layers (Fig. 7B, left plot, Ctrl). However, cutting below the MCL abolished only the oscillations in the GCL (Fig. 7B, right plot, Cut), whereas the spiking activity of mitral/tufted cells remained unaltered (Fig. 7C). This is also apparent on the FFT analysis displays in Figure $7 D$, where both FFT integral and amplitude, computed before and after cutting, showed that oscillations measured in the GCL were dramatically reduced $(n=6 ; p<0.01$ with the paired $t$ test), whereas they were not statistically different in the MCL ( $n=6 ; p>0.05$ with the paired $t$ test). From all experiments, LFP oscillations recorded near the MCL were only slightly reduced (a reduction of $40 \pm 18 \%$ ), whereas those from the GCL were dramatically decreased (a reduction of $87 \pm 7 \%$; Fig. $7 F$ ). Similar data were observed from the cross-correlation between the two signals (Fig. 7E), revealing that, after cutting, the two LFP signals were not statistically different any more (Fig. $7 G$ ), whereas the overall MCL unit firing rate remained constant (Fig. $7 \mathrm{H}$ ). Therefore, the reduction of oscillations in the MCL did not result from a decrease in mitral/tufted cell discharges. Thus, LFP oscillations recorded at the border of the MCL reflected the synchronization of bulbar output neurons that came from the interplay between mitral/tufted cells and granule cells without need of action potentials back-propagating from granule cell somata.

\section{Discussion}

In this study, we characterized the $\mathrm{OB}$ neuronal network that generates $\gamma$ LFP oscillations after brief stimulation of afferent inputs. We examined how oscillatory activity occurs in populations of $\mathrm{OB}$ cells and described precisely the temporal relationship that links the different partners. We found that oscillatory LFP activity was generated by the inhibitory feedback loop provided by granule cells impinging onto mitral/tufted cells. We

demonstrated that GABAergic synaptic events received by the output neurons were phase-locked with field oscillations, and that their blocking suppressed the rhythmic activity. The absence of any temporal correlation between spikes of granule cells and LFP oscillations suggested that a back-propagation of action potentials from their somata was not required for synchronizing bulbar output neurons. We propose that the local dendrodendritic processing in the EPL might be sufficient to generate coherent activity in the OB.

\section{Mechanisms for generating $\gamma$ synchronization in the mammalian $\mathrm{OB}$}

Several modeling studies pointed to the importance of a rapid inhibitory feedback loop in principal neurons for generating $\gamma$ oscillations in the OB (Rall and Shepherd, 1968; Freeman, 1975; Li and Hopfield, 1989; Bazhenov et al., 2001a,b; Davison et al., 2003). In agreement with this, we found that blocking the GABAergic synaptic transmission suppressed $\gamma$ rhythms but increased spike discharges of mitral/tufted cells. In the $\mathrm{OB}$, two populations of GABAergic interneurons mediate inhibition. The more numerous are granule cells that impinge on mitral/tufted lateral dendrites via dendrodendritic synapses in the EPL. The second population, more heterogeneous, is constituted by periglomerular interneurons that contact mitral/tufted apical dendrites also via dendrodendritic synapses (for review, see Shepherd et al., 2004). Recent publications stressed the role of glomerular processing in mitral/tufted cell synchronization responsible for slower $(2-8 \mathrm{~Hz}$ ) field oscillations (Carlson et al., 2000; Puopolo and Belluzzi, 2001; Schoppa and Westbrook, 2001, 2002; Urban and Sakmann, 2002). In contrast to the slow oscillations that do not require granule cell participation, we found that local blockade of $\mathrm{GABA}_{\mathrm{A}}$ receptors in the EPL, but not in the GL, disrupted LFP $\gamma$ oscillations. This is consistent with previous studies showing that field oscillations and associated mitral/tufted cell synchrony are governed by inhibitory activity. Among them are the pharmacological manipulation of inhibition that impairs both LFP oscillations and odor discrimination in honeybees (Stopfer et al., 1997), the genetic manipulation of granule cell excitability that enhances field oscillations and alters discrimination in rodents (Nusser et al., 2001), and the tetanic stimulation of the olfactory nerve that simultaneously enhances both LFP oscillations and inhibitory synaptic events received by mitral/tufted cells (Friedman and Strowbridge, 2003). It is noteworthy that recordings of LFP near the MCL might not reflect modifications occurring in other layers. Thus, we cannot exclude the possibility that periglomerular interneurons contribute to the synchronized activity within the glomerular region.

We have previously found that the GABAergic synaptic transmission and spontaneous subthreshold oscillations of the membrane potential of mitral/tufted cells could interact to synchronize mitral/tufted cell firing activity (Desmaisons et al., 1999). The implication of intrinsic membrane properties in this synchronization was to some extent confirmed by the fact that they were precisely phase-locked with field oscillations. We propose that GABAergic inputs can serve to phase lock subthreshold oscillations that provide a mechanism to integrate excitatory synaptic inputs into action potentials, resulting in a widespread synchronization of mitral/tufted cell action potentials during olfactory responses.

It has been reported that inhibition received by granule cells plays an important role in $\gamma$ field oscillations (Nusser et al., 2001). In line with this, a recent study implicated gap junctions between 

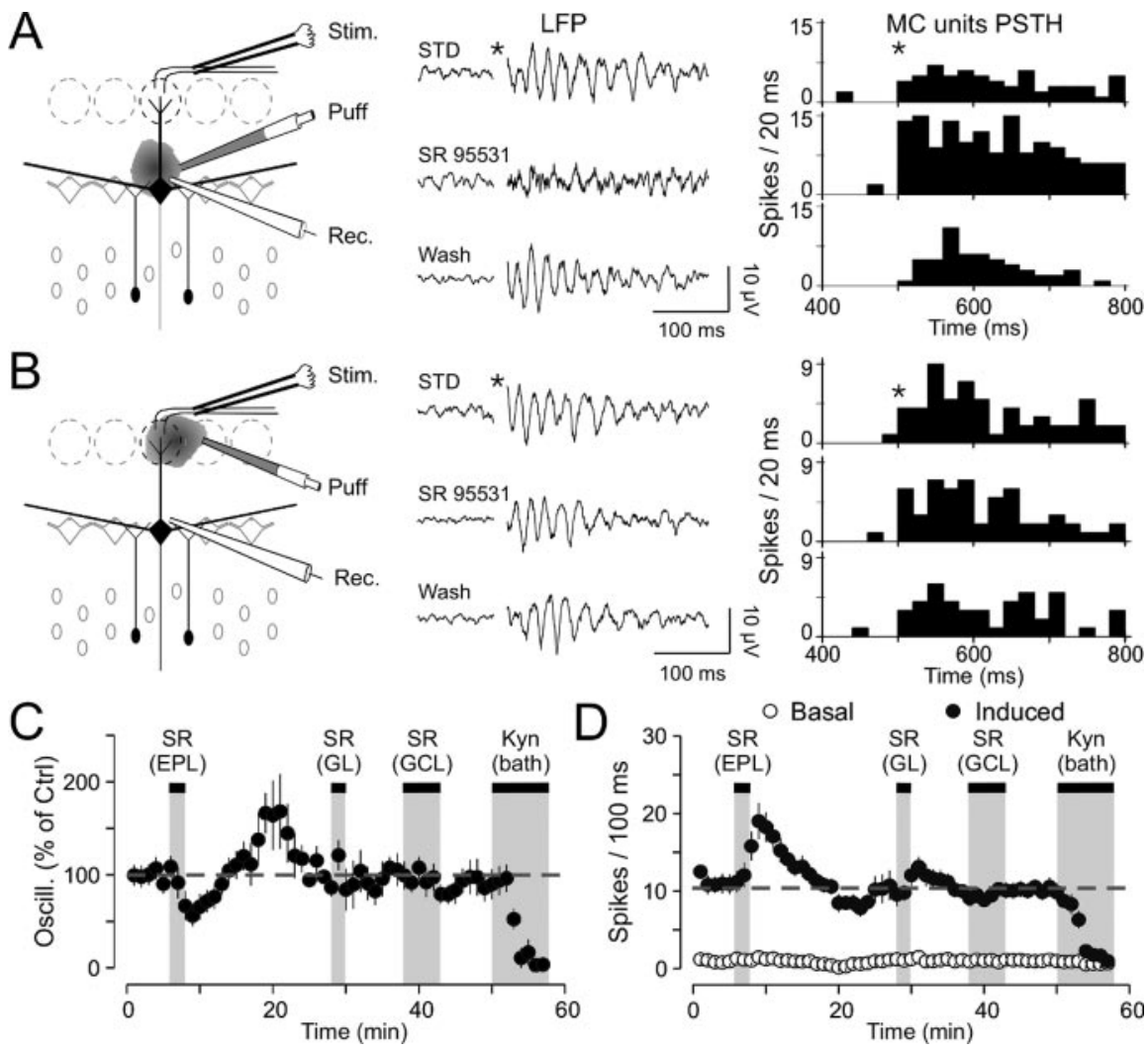

Figure 6. GC inhibition of mitral/tufted cells is a key element for generating LFP oscillations. $A$, Effects of local application of SR95531 in the EPL. Left diagram, Experimental scheme. Middle plot, LFP recordings under different pharmacological conditions. Right plot, PSTH of the mitral/tufted cell (MC) firing activity under the same conditions. Stim., Stimulus; Rec., recording; STD, standard conditions. B, Effects of local application of SR95531 in the GL. Left diagram, Experimental scheme. Middle plot, LFP recordings under different pharmacological conditions. Note the absence of changes in LFP oscillations during SR95531 application. Right plot, PSTH of the mitral/tufted cells firing activity under the same conditions. C, Average of seven experiments showing the evolution of LFP oscillations over time. Note the reduction of oscillations under SR95531 (SR) applications in the EPL and the absence of effect after applications in the other layers. Kyn, Kynurenic acid. D, Average of seven experiments showing the evolution of mitral/tufted cells discharge over time. Note the increase of the discharge after application in the EPL and the slight increase after application in the GL without modification of the baseline line. The dashed line represents the mean induced firing rate in control conditions.

granule cells in the synchronization underlying $\gamma$ oscillations (Friedman and Strowbridge, 2003), yet it is uncertain whether this plays a major role in the oscillations observed here because isolating granule cell spines from their somata did not impair field oscillations. Supporting the notion that granule cell firing might not be required for the induced oscillations is the recent work showing that granule cells have very few action potentials and adapt quickly after the first odor presentation (Cang and Isaacson, 2003). Furthermore, anatomical data on electrical coupling between granule cells are still controversial (Reyher et al., 1991; Paternostro et al., 1995; Kosaka and Kosaka, 2003) and functional evidence is still lacking. Our findings suggest that it might be fruitful to reexamine particularly the role of action potentials generated by granule cells with respect to $\gamma$ oscillations.

\section{Nature of field $\boldsymbol{\gamma}$ oscillations}

Recently, a current source density analysis revealed that the granule cell dipoles provide large current flows during $\gamma$ oscillations (Neville and Haberly, 2003). In line with this, we found that the major part of the currents leading to LFP oscillations came from the EPL, near the MCL, with an inversion below the MCL (Fig. $2 B$ ). However, granule cell spikes did not show strong phasing with LFP oscillations, suggesting that extracellular currents, rather, come from synaptic activity. This is consistent with the fact that the inner third of the EPL contains the greatest density of dendrodendritic reciprocal synapses (Reese, 1966).

The relative contributions of the different electrical events recorded in mitral/ tufted cells (i.e., action potentials, subthreshold oscillations, and synaptic currents) to LFP oscillations is difficult to assess precisely. Membrane subthreshold oscillations of mitral/tufted cells and inhibitory synaptic potentials corresponded to troughs and peaks of LFP oscillations, respectively (Fig. $4 F, G$ ). In contrast, mitral/tufted cell action potentials preferentially occurred during the descending phase of the oscillation (Fig. 3E). These results indicate that spikes might have a weaker contribution to LFP oscillations than synaptic potentials and subthreshold oscillations. Furthermore, we could not exclude a dual participation of interneurons and mitral/tufted cell spiking activity in LFP signals. However, it seems that granule cell synaptic activity, especially excitatory events they receive from mitral/ tufted cells, represents an important component of the electrical signals constituting LFP (Neville and Haberly, 2003).

\section{Bulbar inhibitory interneurons endowed with unique properties} Mitral/tufted cells received IPSPs phased with LFP oscillations, contrasting with a very weak phasing of granule cell action potentials. The fact that LFP and granule cell spiking activity are poorly phased supports the recent finding showing that different epochs can be distinguished according to field oscillation frequencies and cellular activities among the different OB layers (Buonviso et al., 2003).

In our preparation, the paradox between the weak phasing of granule cell spikes with LFP oscillations and the strong correlation between IPSPs and field signals might be explained by the fact that most of the IPSPs were not generated by granule cell action potentials back-propagating from the soma. In agreement with this, it has been previously shown that lateral inhibition could occur without action potentials (Isaacson and Strowbridge, 1998). Moreover, a theoretical study demonstrated that granule cell dendritic trees were functionally compartmentalized (Woolf et al., 1991). This idea was recently supported by experimental evidence showing that calcium transients could spread in limited regions of the dendritic arborizations of hippocampal interneurons (Goldberg et al., 2003). Thus, inhibition arising from granule cells could come either from parts of their dendritic trees, mediating reciprocal as well as lateral inhibition, or from action potentials generated in the soma that back-propagate to the entire dendritic tree (Egger et al., 2003). Our cutting experiment suggests that action potentials from granule cells were not required to generate and maintain LFP oscillations. Nevertheless, the participation of intact remaining granule cells, the involve- 
ment of spikes generated in granule cell dendrites, or both could also explain our results. This unsolved question remains to be further addressed.

Inhibition provided by granule cells exhibits a relatively slow time course (Jahr and Nicoll, 1982; Wellis and Kauer, 1993; Isaacson and Strowbridge, 1998; Schoppa et al., 1998) that is incompatible with $\gamma$ frequencies. However, most IPSPs received by mitral/tufted cells, after olfactory nerve stimulations, are phased with $\gamma$ field oscillations. Taken together, granule cells seem to be able to integrate inputs with different scales over space as well as over time. Fast integration could take place in clustered regions of their dendritic trees, whereas slower integration, leading in some cases to the generation of action potentials, might require the entire cell. These two types of integration may serve different functions. "Fast" inhibition is certainly involved in $\gamma$ oscillations, whereas "slow" inhibition might for instance strengthen $\beta$ or $\theta$ oscillations or both reported by others (Buonviso et al., 2003; Cang and Isaacson, 2003; Margrie and Schaefer, 2003).

\section{$\gamma$ oscillations and olfactory information processing}

Odorants elicit a distributed map of activation confined to single or groups of glomeruli (Kauer and White, 2001). In addition, different compounds often activate nearby or overlapping regions (Yang et al., 1998; Xu et al., 2000; Friedrich and Stopfer, 2001; Kauer and White, 2001; Rubin and Katz, 2001), yet odorants are generally perceived as single objects, implicating a synthetic treatment of this distributed information. This synthesis is widely achieved by synchronizing activated areas into coherent ensembles and is particularly supported by $\gamma$ oscillations (Varela et al., 2001). In the olfactory system, phase locking of unitary activities onto field potential oscillations might play a role in temporal linking of activities for odor-specific neuronal assemblies, as demonstrated in the insect (Laurent and Davidowitz, 1994; Wehr and Laurent, 1996; Perez-Orive et al., 2002). Spatial maps elicited by odorants could thus be converted into coherent objects by synchronizing mitral/tufted cells activated in different glomeruli. The synchrony of groups of neurons is also a means to achieve coherent integration of information over time. In insects, odorants evoke precise, reproducible temporal patterns of activation in projection neurons (Laurent and Davidowitz, 1994; MacLeod and Laurent, 1996). The combination of such individual temporal patterns with the global rhythmic activity offers a powerful means to integrate complex information brought by olfactory stimuli.

Bulbar $\gamma$ activity can be modulated by different means. Oscillations are sensitive to tetanization of excitatory afferents from the olfactory receptor neurons (Friedman and Strowbridge, 2003), actions exerted by neuromodulatory systems (Gray et al., 1986; Gervais et al., 1990), or feedback from the piriform and the entorhinal cortices (Haberly and Price, 1978). This modulation can take part in several processes such as memory [in insects

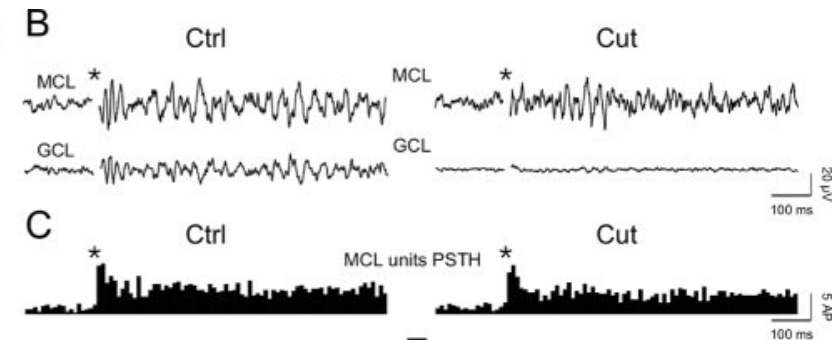

E
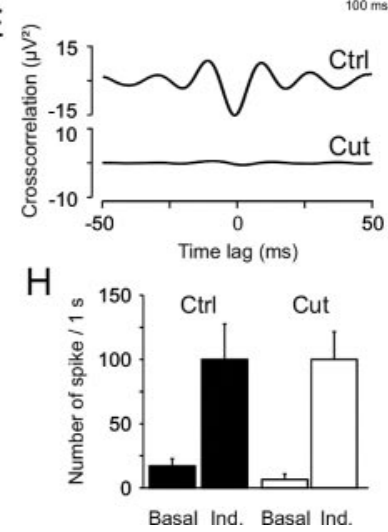

G
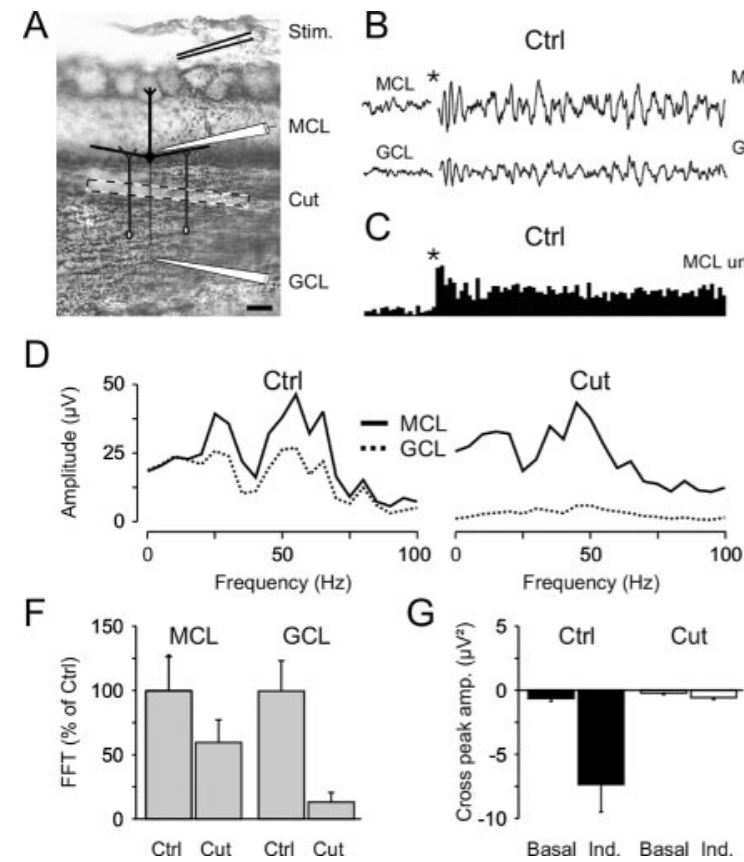

B
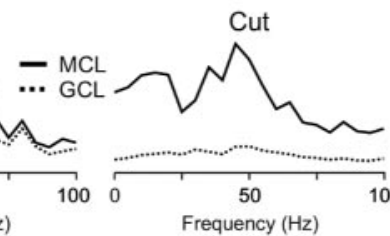

Figure 7. Dendrodendritic reciprocal synapses between $\mathrm{GCs}$ and mitral/tufted cells are sufficient to generate $\gamma$ field oscillations. A, Photomicrograph showing Nissl staining ( $0.5 \%$ cresyl violet) of an $0 B$ slice. The recording configuration and the cut (he signals recorded in the $\mathrm{GCL}$ and $\mathrm{MCL}$ locations before and after the cut (top, bottom Effect of cutting on the correlation between the two recording sites. After the cut, the correlation remains similar before (Basal) and after (Ind.) the stimulation. H, Absence of effect of cutting on the basal and induced (Ind.) mitral/tufted cells discharges.

(Stopfer and Laurent, 1999) and in mammals (Ravel et al., 2003)] and habituation (Gray and Skinner, 1988). In line with this, granule cells, among the key elements for generating LFP oscillations, undergo a permanent renewal (Altman, 1969). Up to 80,000 newborn cells populate the OB per day (Kaplan et al., 1985) (for review, see Peterson, 2002). It would thus be of great interest to evaluate the impact of this neuronal recruitment on odor information processing and to understand how such processing remains constant in a dynamic network.

\section{References}

Adrian ED (1942) Olfactory reactions in the brain of the hedgehog. J Physiol (Lond) 100:459-473.

Altman J (1969) Autoradiographic and histological studies of postnatal neurogenesis. IV. Cell proliferation and migration in the anterior forebrain, with special reference to persisting neurogenesis in the olfactory bulb. J Comp Neurol 137:433-457.

Bazhenov M, Stopfer M, Rabinovich M, Huerta R, Abarbanel HD, Sejnowski TJ, Laurent G (2001a) Model of transient oscillatory synchronization in the locust antennal lobe. Neuron 30:553-567.

Bazhenov M, Stopfer M, Rabinovich M, Abarbanel HD, Sejnowski TJ, Laurent G (2001b) Model of cellular and network mechanisms for odorevoked temporal patterning in the locust antennal lobe. Neuron 30:569-581.

Becker CJ, Freeman WJ (1968) Prepyriform electrical activity after loss of peripheral or central input, or both. Physiol Behav 3:597-599.

Bressler SL (1984) Spatial organization of EEGs from olfactory bulb and cortex. Electroencephalogr Clin Neurophysiol 57:270-276.

Bressler SL, Freeman WJ (1980) Frequency analysis of olfactory system EEG in cat, rabbit, and rat. Electroencephalogr Clin Neurophysiol 50:19-24.

Buonviso N, Amat C, Litaudon P, Roux S, Royet JP, Farget V, Sicard G 
(2003) Rhythm sequence through the olfactory bulb layers during the time window of a respiratory cycle. Eur J Neurosci 17:1811-1819.

Cang J, Isaacson JS (2003) In vivo whole-cell recording of odor-evoked synaptic transmission in the rat olfactory bulb. J Neurosci 23:4108-4116.

Carlson GC, Shipley MT, Keller A (2000) Long-lasting depolarizations in mitral cells of the rat olfactory bulb. J Neurosci 20:2011-2021.

Castillo PE, Carleton A, Vincent JD, Lledo P-M (1999) Multiple and opposing roles of cholinergic transmission in the main olfactory bulb. J Neurosci 19:9180-9191.

Chabaud P, Ravel N, Wilson DA, Mouly AM, Vigouroux M, Farget V, Gervais R (2000) Exposure to behaviourally relevant odour reveals differential characteristics in rat central olfactory pathways as studied through oscillatory activities. Chem Senses 25:561-573.

Chen WR, Shepherd GM (1997) Membrane and synaptic properties of mitral cells in slices of rat olfactory bulb. Brain Res 745:189-196.

Davison AP, Feng J, Brown D (2003) Dendrodendritic inhibition and simulated odor responses in a detailed olfactory bulb network model. J Neurophysiol 90:1921-1935.

Desmaisons D, Vincent JD, Lledo PM (1999) Control of action potential timing by intrinsic subthreshold oscillations in olfactory bulb output neurons. J Neurosci 19:10727-10737.

Eeckman FH, Freeman WJ (1990) Correlations between unit firing and EEG in the rat olfactory system. Brain Res 528:238-244.

Egger V, Svoboda K, Mainen ZF (2003) Mechanisms of lateral inhibition in the olfactory bulb: efficiency and modulation of spike-evoked calcium influx into granule cells. J Neurosci 23:7551-7558.

Fisher NI (1993) Statistical analysis of circular data. Cambridge UK: Cambridge UP.

Freeman WJ (1975) Mass action in the nervous system. New York: Academic.

Freeman WJ, Schneider W (1982) Changes in spatial patterns of rabbit olfactory EEG with conditioning to odors. Psychophysiology 19:44-56.

Friedman D, Strowbridge BW (2003) Both electrical and chemical synapses mediate fast network oscillations in the olfactory bulb. J Neurophysiol 89:2601-2610.

Friedrich RW, Stopfer M (2001) Recent dynamics in olfactory population coding. Curr Opin Neurobiol 11:468-474.

Gervais R, Mouly AM, Elaagouby K, Levy F (1990) Olfactory bulb plasticity. In: Chemosensory information processing (Schild D, ed), pp 191-200. Berlin: Springer.

Goldberg JH, Yuste R, Tamas G (2003) Ca2 + imaging of mouse neocortical interneurone dendrites: contribution of $\mathrm{Ca} 2+$-permeable AMPA and NMDA receptors to subthreshold Ca2+dynamics. J Physiol (Lond) 551:67-78.

Gray CM (1994) Synchronous oscillations in neuronal systems: mechanisms and functions. J Comput Neurosci 1:11-38.

Gray CM, Skinner JE (1988) Centrifugal regulation of neuronal activity in the olfactory bulb of the waking rabbit as revealed by reversible cryogenic blockade. Exp Brain Res 69:378-386.

Gray CM, Freeman WJ, Skinner JE (1986) Chemical dependencies of learning in the rabbit olfactory bulb: acquisition of the transient spatial pattern change depends on norepinephrine. Behav Neurosci 100:585-596.

Haberly LB, Price JL (1978) Association and commissural fiber systems of the olfactory cortex of the rat. I. Systems originating in the piriform cortex and adjacent areas. J Comp Neurol 178:711-740.

Halabisky B, Friedman D, Radojicic M, Strowbridge BW (2000) Calcium influx through NMDA receptors directly evokes GABA release in olfactory bulb granule cells. J Neurosci 20:5124-5134.

Hayar A, Karnup S, Shipley MT, Ennis M (2004) Olfactory bulb glomeruli: external tufted cells intrinsically burst at theta frequency and are entrained by patterned olfactory input. J Neurosci 24:1190-1199.

Isaacson JS, Strowbridge BW (1998) Olfactory reciprocal synapses: dendritic signaling in the CNS. Neuron 20:749-761.

Jahr CE, Nicoll RA (1982) An intracellular analysis of dendrodendritic inhibition in the turtle in vitro olfactory bulb. J Physiol (Lond) 326:213-234.

Kaplan MS, McNelly NA, Hinds JW (1985) Population dynamics of adultformed granule neurons of the rat olfactory bulb. J Comp Neurol 239:117-125.

Kashiwadani H, Sasaki YF, Uchida N, Mori K (1999) Synchronized oscilla- tory discharges of mitral/tufted cells with different molecular receptive ranges in the rabbit olfactory bulb. J Neurophysiol 82:1786-1792.

Kauer JS, White J (2001) Imaging and coding in the olfactory system. Annu Rev Neurosci 24:963-979.

Korsching S (2002) Olfactory maps and odor images. Curr Opin Neurobiol 12:387-392.

Kosaka T, Kosaka K (2003) Neuronal gap junctions in the rat main olfactory bulb, with special reference to intraglomerular gap junctions. Neurosci Res 45:189-209.

Laurent G (2002) Olfactory network dynamics and the coding of multidimensional signals. Nat Rev Neurosci 3:884-895.

Laurent G, Davidowitz H (1994) Encoding of olfactory information with oscillating neural assemblies. Science 265:1872-1875.

Laurent G, Naraghi M (1994) Odorant-induced oscillations in the mushroom bodies of the locust. J Neurosci 14:2993-3004.

Leon M, Johnson BA (2003) Olfactory coding in the mammalian olfactory bulb. Brain Res Rev 42:23-32.

Li Z, Hopfield JJ (1989) Modeling the olfactory bulb and its neural oscillatory processings. Biol Cybern 61:379-392.

MacLeod K, Laurent G (1996) Distinct mechanisms for synchronization and temporal patterning of odor-encoding neural assemblies. Science 274:976-979.

MacQuiston AR, Katz LC (2001) Electrophysiology of interneurons in the glomerular layer of the rat olfactory bulb. J Neurophysiol 86:1899-18907.

Margrie TW, Schaefer AT (2003) Theta oscillation coupled spike latencies yield computational vigour in a mammalian sensory system. J Physiol (Lond) 546:363-374.

Mori K, Takagi SF (1977) Inhibition in the olfactory bulb: dendrodendritic interaction and their relation to the induced waves. In: Food intake and chemical senses (Katsuki K, Sato M, Takagi SF, Oomura Y, eds), pp 3343. Tokyo: University of Tokyo.

Neville KR, Haberly LB (2003) Beta and gamma oscillations in the olfactory system of the urethane-anesthetized rat. J Neurophysiol 90:3921-3930.

Nikonov AA, Parker JM, Caprio J (2002) Odorant-induced olfactory receptor neural oscillations and their modulation of olfactory bulbar responses in the channel catfish. J Neurosci 22:2352-2362.

Nusser Z, Kay LM, Laurent G, Homanics GE, Mody I (2001) Disruption of GABAA receptors on GABAergic interneurons leads to increased oscillatory power in the olfactory bulb network. J Neurophysiol 86:2823-2833.

Paternostro MA, Reyher CK, Brunjes PC (1995) Intracellular injections of Lucifer yellow into lightly fixed mitral cells reveal neuronal dye-coupling in the developing rat olfactory bulb. Dev Brain Res 84:1-10.

Perez-Orive J, Mazor O, Turner GC, Cassenaer S, Wilson RI, Laurent G (2002) Oscillations and sparsening of odor representations in the mushroom body. Science 297:359-365.

Peterson DA (2002) Stem cells in brain plasticity and repair. Curr Opin Pharmacol 2:34-42.

Puopolo M, Belluzzi O (2001) NMDA-dependent, network-driven oscillatory activity induced by bicuculline or removal of $\mathrm{Mg}^{2+}$ in rat olfactory bulb neurons. Eur J Neurosci 13:92-102.

Rall W, Shepherd GM (1968) Theoretical reconstruction of field potentials and dendrodendritic synaptic interactions in olfactory bulb. J Neurophysiol 31:884-915.

Ravel N, Chabaud P, Martin C, Gaveau V, Hugues E, Tallon-Baudry C, Bertrand O, Gervais R (2003) Olfactory learning modifies the expression of odour-induced oscillatory responses in the gamma $(60-90 \mathrm{~Hz})$ and beta $(15-40 \mathrm{~Hz})$ bands in the rat olfactory bulb. Eur J Neurosci $17: 350-358$.

Reese TS (1966) Further studies on dendrodendritic synapses in the olfactory bulb. Anat Rec 154:408.

Reyher CK, Lubke J, Larsen WJ, Hendrix GM, Shipley MT, Baumgarten HG (1991) Olfactory bulb granule cell aggregates: morphological evidence for interperikaryal electrotonic coupling via gap junctions. J Neurosci 11:1485-1495.

Rubin BD, Katz LC (2001) Spatial coding of enantiomers in the rat olfactory bulb. Nat Neurosci 4:355-356.

Schoppa NE, Westbrook GL (2001) Glomerulus-specific synchronization of mitral cells in the olfactory bulb. Neuron 31:639-651.

Schoppa NE, Westbrook GL (2002) AMPA autoreceptors drive correlated spiking in olfactory bulb glomeruli. Nat Neurosci 5:1194-1202.

Schoppa NE, Kinzie JM, Sahara Y, Segerson TP, Westbrook GL (1998) Den- 
drodendritic inhibition in the olfactory bulb is driven by NMDA receptors. J Neurosci 18:6790-6802.

Shepherd GM, Chen RC, Greer CA (2004) Olfactory bulb. In: The synaptic organization of the brain (Shepherd GM, ed), pp 165-216. New York: Oxford UP.

Stopfer M, Laurent G (1999) Short-term memory in olfactory network dynamics. Nature 402:664-668.

Stopfer M, Bhagavan S, Smith BH, Laurent G (1997) Impaired odour discrimination on desynchronization of odour-encoding neural assemblies. Nature 390:70-74.

Urban NN, Sakmann B (2002) Reciprocal intraglomerular excitation and intra- and interglomerular lateral inhibition between mouse olfactory bulb mitral cells. J Physiol (Lond) 542:355-367.

Varela F, Lachaux JP, Rodriguez E, Martinerie J (2001) The brainweb: phase synchronization and large-scale integration. Nat Rev Neurosci 2:229-239.
Wehr M, Laurent G (1996) Odour encoding by temporal sequences of firing in oscillating neural assemblies. Nature 384:162-166.

Wellis DP, Kauer JS (1993) GABAA and glutamate receptor involvement in dendrodendritic synaptic interactions from salamander olfactory bulb. J Physiol (Lond) 469:315-339.

Woolf TB, Shepherd GM, Greer CA (1991) Local information processing in dendritic trees: subsets of spines in granule cells of the mammalian olfactory bulb. J Neurosci 11:1837-1854.

Xu F, Kida I, Hyder H, Shulman RG (2000) Assessment and discrimination of odor stimuli in rat olfactory bulb by dynamic functional MRI. Proc Natl Acad Sci USA 97:10601-10606.

Yang X, Renken R, Hyder F, Siddeek M, Greer CA, Shepherd GM, Shulman RG (1998) Dynamic mapping at the laminar level of odor-elicited responses in rat olfactory bulb by functional MRI. Proc Natl Acad Sci USA 95:7715-7720. 